Supporting Information

\title{
Inactivation of Bacteria by Peracetic Acid Combined with UV Irradiation: Mechanism and Optimization
}

Tianqi Zhang, Ting Wang, Benjamin Mejia-Tickner, Jessica Kissel, Xing Xie, and Ching-Hua Huang ${ }^{*}$

School of Civil and Environmental Engineering, Georgia Institute of Technology, Atlanta, Georgia 30332, United States

*Corresponding Author.

Phone: 404-894-7694. E-mail: ching-hua.huang@,ce.gatech.edu

Content:

Text: S1-S2

Tables: S1

Figures: S1-S14

References: 25

Pages: 16 


\section{Text S1. Chemicals and reagents}

$\mathrm{H}_{2} \mathrm{O}_{2}$ (wt. $30 \%$ in $\mathrm{H}_{2} \mathrm{O}$ ), $\mathrm{NaCl}(\geq 99.5 \%$ ), tert-butyl alcohol (TBA) (99.5\%) and peroxidase from horseradish (50-150 units/mg) were purchased from Sigma Aldrich Inc. (St. Louis, MO). $\mathrm{Na}_{2} \mathrm{~S}_{2} \mathrm{O}_{3}, \mathrm{Na}_{2} \mathrm{HPO}_{4}$ and $\mathrm{NaH}_{2} \mathrm{PO}_{4}$ were obtained from Fisher Scientific Co. (Hampton, $\mathrm{NH}$ ). Difco $^{\mathrm{TM}}$ LB broth and agar (for Escherichia coli), BBL brain heart infusion and agar (for Enterococcus durans), and Difco nutrient broth and agar (for Staphylococcus epidermidis) were obtained from VWR International Inc. (Radnor, PA). Eosin methylene blue (EMB) agar (selective for E. coli) was obtained from Sigma Aldrich Inc. (St. Louis, MO). BBL Enterococcosel agar (selective for Enterococcus) was obtained from VWR International Inc. (Radnor, PA). Mannitol salt agar (selective for Staphylococcus) was obtained from Research Products International (RPI) (Mt. Prospect, IL). Phosphate buffered saline (PBS) was prepared with $150 \mathrm{mM}$ sodium phosphate and $150 \mathrm{mM}$ sodium chloride at $\mathrm{pH}$ 7.2.

\section{Text S2. Culturing and plating of bacteria}

Detailed procedure of culture preparation was provided in our previous work. ${ }^{1}$ Briefly, bacterial strain was inoculated in corresponding broth and grown for $18 \mathrm{~h}$ at $37^{\circ} \mathrm{C}$. The culture was then washed by the PBS, followed by phosphate buffer (PB) (30 mM at pH 7.2) before use. The absorbance of washed cell suspension at $600 \mathrm{~nm}$ was measured to estimate cell density in order to achieve a consistent initial cell density $\left(\sim 5 \times 10^{7} \mathrm{CFU} \cdot \mathrm{mL}^{-1}\right)$ in the reactor.

The reactor solution was prepared by spiking PAA and/or $\mathrm{H}_{2} \mathrm{O}_{2}$ into the $\mathrm{PB}(3.0 \mathrm{mM}$ at $\mathrm{pH} 7.1)$ or wastewater effluent. Then, disinfection experiments were initiated by spiking cell suspension into the reactor and exposing the reactor under UV light if needed. Preliminary tests showed that the $\mathrm{pH}$ was stable during the disinfection experiments. Samples (50 or $100 \mu \mathrm{L}$ as needed) were drawn periodically from the reactor and quenched immediately with excess sodium thiosulfate $\left(\left[\mathrm{Na}_{2} \mathrm{~S}_{2} \mathrm{O}_{3}\right]>5 \times\left([\mathrm{PAA}]+\left[\mathrm{H}_{2} \mathrm{O}_{2}\right]\right)\right.$ in $\left.\mathrm{M}\right){ }^{2}$ In this work, 0.5 or $1.0 \mathrm{mM} \mathrm{Na} \mathrm{S}_{2} \mathrm{O}_{3}$ was applied accordingly. For each sample, a ten-fold serial dilution was performed up to $1 / 100,000$ dilution ratio using $30 \mathrm{mM}$ PBS. 50 or $100 \mu \mathrm{L}$ of each diluted sample was plated on sterile Petri dishes containing corresponding agar. The Petri dishes loaded with samples were sealed with Ziploc bags and incubated at $35{ }^{\circ} \mathrm{C}$ for 18 to $24 \mathrm{~h}$ before counting for the colony forming units (CFU). The controls containing cells (i.e., E. coli, E. durans, or S. epidermidis) and $1.0 \mathrm{mM} \mathrm{Na} \mathrm{S}_{2} \mathrm{O}_{3}$ were

plated following the same procedure and no interference was observed by $1.0 \mathrm{mM} \mathrm{Na} 2 \mathrm{~S}_{2} \mathrm{O}_{3}$ on the 
propagation of all three microorganisms.

Table S1. List of the identified major elementary reaction pathways and the reaction rate constant under UV/PAA. ${ }^{3}$

\begin{tabular}{|c|c|c|c|}
\hline & & $k\left(\mathrm{M}^{-1} \mathrm{~s}^{-1}\right)$ & reference \\
\hline & $\mathrm{UV} / \mathrm{H}_{2} \mathrm{O}_{2}$ system & & \\
\hline R1 & $\mathrm{H}_{2} \mathrm{O}_{2}+\mathrm{h} v \rightarrow 2^{\bullet} \mathrm{OH}$ & $\begin{array}{l}\varepsilon=18.7 \mathrm{M}^{-1} \mathrm{~cm}^{-1} \\
\Phi=0.5 \mathrm{~mol} \mathrm{Ein}^{-1}\end{array}$ & 4 \\
\hline $\mathrm{R} 2$ & $\bullet \mathrm{OH}+\mathrm{H}_{2} \mathrm{O}_{2} \rightarrow \mathrm{HO}_{2}^{\bullet}+\mathrm{H}_{2} \mathrm{O}$ & $2.7 \times 10^{7}$ & 5 \\
\hline R3 & $\bullet \mathrm{OH}+\mathrm{HO}_{2}^{-} \rightarrow \mathrm{O}_{2}^{\bullet-}+\mathrm{H}_{2} \mathrm{O}$ & $7.5 \times 10^{9}$ & 5 \\
\hline $\mathrm{R} 4$ & $\bullet \mathrm{OH}+\mathrm{HO}_{2}^{\bullet} \rightarrow \mathrm{O}_{2}+\mathrm{H}_{2} \mathrm{O}$ & $6.6 \times 10^{9}$ & 5 \\
\hline R5 & $\cdot \mathrm{OH}+\mathrm{O}_{2}^{\bullet-} \rightarrow \mathrm{O}_{2}+\mathrm{OH}^{-}$ & $8.0 \times 10^{9}$ & 5 \\
\hline R6 & $\bullet \mathrm{OH}+\cdot{ }^{\bullet} \mathrm{OH} \rightarrow \mathrm{H}_{2} \mathrm{O}_{2}$ & $5.5 \times 10^{9}$ & 5 \\
\hline R7 & $\cdot \mathrm{OH}+\mathrm{HCO}_{3}^{-} \rightarrow \mathrm{CO}_{3}{ }^{\bullet-}+\mathrm{H}_{2} \mathrm{O}$ & $8.5 \times 10^{6}$ & 5 \\
\hline $\mathrm{R} 8$ & $\cdot \mathrm{OH}+\mathrm{CO}_{3}^{2-} \rightarrow \mathrm{CO}_{3}{ }^{\bullet-}+\mathrm{OH}^{-}$ & $3.9 \times 10^{8}$ & 5 \\
\hline R9 & $\cdot \mathrm{OH}+\mathrm{CO}_{3}{ }^{\bullet-} \rightarrow$ products & $3.0 \times 10^{9}$ & 6 \\
\hline R10 & 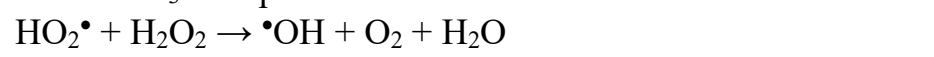 & 3.7 & 7 \\
\hline R11 & $\mathrm{HO}_{2}^{\bullet}+\mathrm{HO}_{2}^{\bullet} \rightarrow \mathrm{H}_{2} \mathrm{O}_{2}+\mathrm{O}_{2}$ & $8.6 \times 10^{5}$ & 8 \\
\hline R12 & $\mathrm{O}_{2}^{\bullet-}+\mathrm{H}_{2} \mathrm{O}_{2} \rightarrow \cdot \mathrm{OH}+\mathrm{O}_{2}+\mathrm{OH}^{-}$ & 0.13 & 7 \\
\hline R13 & $\mathrm{O}_{2}^{\bullet-}+\mathrm{HO}_{2}^{\bullet} \rightarrow \mathrm{H}_{2} \mathrm{O}^{-}+\mathrm{O}_{2}$ & $9.7 \times 10^{7}$ & 7 \\
\hline $\mathrm{R} 14$ & $\mathrm{O}_{2}^{\bullet-}+\mathrm{CO}_{3}^{\bullet-} \rightarrow \mathrm{O}_{2}+\mathrm{CO}_{3}^{2-}$ & $6.5 \times 10^{8}$ & 9 \\
\hline R15 & $\mathrm{CO}_{3}^{\bullet-}+\mathrm{H}_{2} \mathrm{O}_{2} \rightarrow \mathrm{HCO}_{3}^{-}+\mathrm{O}_{2}^{\bullet-}+\mathrm{H}^{+}$ & $8.0 \times 10^{5}$ & 10 \\
\hline $\mathrm{R} 16$ & $\mathrm{CO}_{3}^{\bullet-}+\mathrm{H}_{2} \mathrm{O}^{-} \rightarrow \mathrm{HCO}_{3}^{-}+\mathrm{O}_{2}^{\bullet-}$ & $3.0 \times 10^{7}$ & 10 \\
\hline R17 & $\mathrm{CO}_{3}{ }^{--}+\mathrm{CO}_{3}^{{ }^{--}} \rightarrow 2 \mathrm{CO}_{3}^{2-}$ & $2.0 \times 10^{7}$ & 10 \\
\hline R18 & $\mathrm{H}_{2} \mathrm{O}_{2} \leftrightarrow \mathrm{HO}_{2}^{-}+\mathrm{H}^{+}$ & $2.51 \times 10^{-2} \mathrm{~s}^{-1}$ & 11 \\
\hline $\mathrm{R} 18 \mathrm{r}$ & & $1.0 \times 10^{10}$ & \\
\hline R19 & $\mathrm{HO}_{2}^{\bullet} \leftrightarrow \mathrm{O}_{2}^{\bullet-}+\mathrm{H}^{+}$ & $1.58 \times 10^{5} \mathrm{~s}^{-1}$ & 11 \\
\hline $\mathrm{R} 19 \mathrm{r}$ & & $1.0 \times 10^{10}$ & \\
\hline $\mathrm{R} 20$ & $\mathrm{CO}_{2}(\mathrm{aq})+\mathrm{H}_{2} \mathrm{O} \leftrightarrow \mathrm{H}_{2} \mathrm{CO}_{3}$ & $0.039 \mathrm{~s}^{-1}$ & 12 \\
\hline $\mathrm{R} 20 \mathrm{r}$ & & 23 & \\
\hline $\mathrm{R} 21$ & $\mathrm{H}_{2} \mathrm{CO}_{3} \leftrightarrow \mathrm{HCO}_{3}^{-}+\mathrm{H}^{+}$ & $1.25 \times 10^{7} \mathrm{~s}^{-1}$ & 13 \\
\hline $\mathrm{R} 21 \mathrm{r}$ & & $5 \times 10^{10}$ & \\
\hline $\mathrm{R} 22$ & ${ }^{\bullet} \mathrm{OH}+\mathrm{H}_{2} \mathrm{PO}_{4}^{-} \rightarrow \mathrm{HPO}_{4}^{-}+\mathrm{H}_{2} \mathrm{O}$ & $2.0 \times 10^{4}$ & 14 \\
\hline $\mathrm{R} 23$ & $\cdot \mathrm{OH}+\mathrm{HPO}_{4}^{2-} \rightarrow \mathrm{HPO}_{4}{ }^{\bullet-}+\mathrm{OH}^{-}$ & $1.5 \times 10^{5}$ & 14 \\
\hline R24 & $\mathrm{H}_{2} \mathrm{O}_{2}+\mathrm{HPO}_{4}^{\bullet-} \rightarrow \mathrm{H}_{2} \mathrm{PO}_{4}^{-}+\mathrm{HO}_{2}{ }^{\bullet}$ & $2.7 \times 10^{7}$ & 15 \\
\hline $\mathrm{R} 25$ & $\mathrm{H}_{2} \mathrm{PO}_{4}^{-} \leftrightarrow \mathrm{HPO}_{4}^{2-}+\mathrm{H}^{+}$ & $3.2 \times 10^{3} \mathrm{~s}^{-1}$ & 16 \\
\hline $\mathrm{R} 25 \mathrm{r}$ & & $5 \times 10^{10}$ & \\
\hline & Acetate and ${ }^{\bullet} \mathrm{OH}$ initiated reactions & & \\
\hline R26 & $\mathrm{CH}_{3} \mathrm{C}(\mathrm{O}) \mathrm{OH}+{ }^{\bullet} \mathrm{OH} \rightarrow{ }^{\bullet} \mathrm{CH}_{2} \mathrm{C}(\mathrm{O}) \mathrm{OH}+\mathrm{H}_{2} \mathrm{O}$ & $1.6 \times 10^{7}$ & 5 \\
\hline $\mathrm{R} 27$ & $\mathrm{CH}_{3} \mathrm{C}(\mathrm{O}) \mathrm{O}^{-}+\cdot{ }^{\bullet} \mathrm{OH} \rightarrow{ }^{\bullet} \mathrm{CH}_{2} \mathrm{C}(\mathrm{O}) \mathrm{O}^{-}+\mathrm{H}_{2} \mathrm{O}$ & $8.5 \times 10^{7}$ & 5 \\
\hline R28 & $\cdot \mathrm{CH}_{2} \mathrm{C}(\mathrm{O}) \mathrm{O}^{-}+\mathrm{O}_{2} \rightarrow \cdot{ }^{\cdot} \mathrm{OOCH}_{2} \mathrm{C}(\mathrm{O}) \mathrm{O}^{-}$ & $1.7 \times 10^{9}$ & 17 \\
\hline R29 & $\cdot \mathrm{OOCH}_{2} \mathrm{C}(\mathrm{O}) \mathrm{O}^{-}+\cdot \mathrm{OOCH}_{2} \mathrm{C}(\mathrm{O}) \mathrm{O}^{-} \rightarrow$ products & $2.6 \times 10^{8}$ & 18 \\
\hline $\mathrm{R} 30$ & $\cdot \mathrm{OOCH}_{2} \mathrm{C}(\mathrm{O}) \mathrm{O}^{-}+\mathrm{HO}_{2} \cdot \rightarrow \mathrm{HOCH}_{2} \mathrm{C}(\mathrm{O}) \mathrm{O}^{-}+{ }^{3} \mathrm{O}+{ }^{3} \mathrm{O}_{2}$ & $1.0 \times 10^{5}$ & 19 \\
\hline $\mathrm{R} 31$ & $\begin{array}{l}{ }^{\circ} \mathrm{OCH}_{2} \mathrm{C}(\mathrm{O}) \mathrm{O}^{-} \\
\mathrm{HOCC}(\mathrm{O}) \mathrm{O}^{-}\end{array}$ & $7.3 \times 10^{9}$ & 19 \\
\hline R32 & $\cdot \mathrm{OCH}_{2} \mathrm{C}(\mathrm{O}) \mathrm{O}^{-} \rightarrow \mathrm{HCHO}+{ }^{\bullet} \mathrm{C}(\mathrm{O}) \mathrm{O}^{-}$ & $1.0 \times 10^{6} \mathrm{~s}^{-1}$ & 19 \\
\hline $\mathrm{R} 33$ & $\cdot \mathrm{C}(\mathrm{O}) \mathrm{O}^{-}+\mathrm{O}_{2} \rightarrow \mathrm{CO}_{2}+{ }^{\bullet} \mathrm{O}_{2}^{-}$ & $2.4 \times 10^{9}$ & 7 \\
\hline
\end{tabular}




\begin{tabular}{|c|c|c|c|}
\hline R34 & $\mathrm{HOCC}(\mathrm{O}) \mathrm{O}^{-}+{ }^{\bullet} \mathrm{OH} \rightarrow{ }^{\bullet} \mathrm{OCC}(\mathrm{O}) \mathrm{O}^{-}+\mathrm{H}_{2} \mathrm{O}$ & $2.6 \times 10^{9}$ & 20 \\
\hline R35 & $\mathrm{HOCH}_{2} \mathrm{C}(\mathrm{O}) \mathrm{O}^{-}+{ }^{\bullet} \mathrm{OH} \rightarrow \mathrm{HO}^{\bullet} \mathrm{CHC}(\mathrm{O}) \mathrm{O}^{-}+\mathrm{H}_{2} \mathrm{O}$ & $8.6 \times 10^{8}$ & 5 \\
\hline R36 & $\mathrm{HCHO}+{ }^{\bullet} \mathrm{OH} \rightarrow$ products & $1.0 \times 10^{9}$ & 5 \\
\hline R37 & $\begin{array}{l}\text { UV/PAA system } \\
\mathrm{CH}_{3} \mathrm{C}(\mathrm{O}) \mathrm{OOH}+\mathrm{h} v \rightarrow \mathrm{CH}_{3} \mathrm{C}(\mathrm{O}) \mathrm{O}^{\bullet}+\cdot{ }^{\bullet} \mathrm{OH}\end{array}$ & $\begin{array}{c}\varepsilon=8.0 \mathrm{M}^{-1} \mathrm{~cm}^{-1} \\
\Phi=0.88 \mathrm{~mol} \mathrm{Ein}^{-1}\end{array}$ & 3 \\
\hline R38 & $\mathrm{CH}_{3} \mathrm{C}(\mathrm{O}) \mathrm{OOH}+\bullet \cdot \mathrm{OH} \rightarrow \mathrm{CH}_{3} \mathrm{C}(\mathrm{O}) \mathrm{OO} \bullet+\mathrm{H}_{2} \mathrm{O}$ & $1.3 \times 10^{9}$ & 3 \\
\hline R39 & $\begin{array}{l}\mathrm{CH}_{3} \mathrm{C}(\mathrm{O}) \mathrm{OOH} \\
\mathrm{CH}_{3} \mathrm{C}(\mathrm{O}) \mathrm{OH}\end{array}$ & $1.0 \times 10^{7}$ & $\begin{array}{c}21 \\
3\end{array}$ \\
\hline R40 & $\mathrm{CH}_{3} \mathrm{C}(\mathrm{O}) \mathrm{OOH}+\mathrm{HO}_{2}^{\bullet} \rightarrow \mathrm{CH}_{3} \mathrm{C}(\mathrm{O}) \mathrm{OO} \bullet+\mathrm{H}_{2} \mathrm{O}_{2}$ & $2.0 \times 10^{2}$ & 3 \\
\hline R41 & $\mathrm{CH}_{3} \mathrm{C}(\mathrm{O}) \mathrm{OO}^{\bullet}+\mathrm{CH}_{3} \mathrm{C}(\mathrm{O}) \mathrm{OO}^{\bullet} \rightarrow 2 \mathrm{CH}_{3} \mathrm{C}(\mathrm{O}) \mathrm{O}^{\bullet}+\mathrm{O}_{2}$ & $8.3 \times 10^{9}$ & 19 \\
\hline R42 & $\mathrm{CH}_{3} \mathrm{C}(\mathrm{O}) \mathrm{OO} \cdot+\mathrm{HO}_{2}{ }^{\bullet} \rightarrow \mathrm{CH}_{3} \mathrm{C}(\mathrm{O}) \mathrm{OH}+{ }^{3} \mathrm{O}+{ }^{3} \mathrm{O}_{2}$ & $2.0 \times 10^{6}$ & 19 \\
\hline R43 & $\mathrm{CH}_{3} \mathrm{C}(\mathrm{O}) \mathrm{OO} \cdot \rightarrow \mathrm{HO}_{2} \cdot+\mathrm{CH}_{2} \mathrm{CO}$ & $1.82 \mathrm{~s}^{-1}$ & 19 \\
\hline R44 & $\mathrm{CH}_{2} \mathrm{CO}+\mathrm{H}_{2} \mathrm{O} \rightarrow \mathrm{CH}_{3} \mathrm{C}(\mathrm{O}) \mathrm{OH}$ & $44 \mathrm{~s}^{-1}$ & 19 \\
\hline R45 & $\mathrm{CH}_{3} \mathrm{C}(\mathrm{O}) \mathrm{O}^{\bullet}+\mathrm{CH}_{3} \mathrm{C}(\mathrm{O}) \mathrm{O}^{\bullet} \rightarrow\left(\mathrm{CH}_{3} \mathrm{C}(\mathrm{O}) \mathrm{O}\right)_{2}$ & $1.0 \times 10^{9}$ & 21 \\
\hline R46 & $\mathrm{CH}_{3} \mathrm{C}(\mathrm{O}) \mathrm{O}^{\bullet} \rightarrow{ }^{\bullet} \mathrm{CH}_{3}+\mathrm{CO}_{2}$ & $2.3 \times 10^{5} \mathrm{~s}^{-1}$ & 22 \\
\hline R47 & $\cdot \mathrm{CH}_{3}+\mathrm{O}_{2} \rightarrow \cdot \mathrm{OOCH}_{3}$ & $4.7 \times 10^{9}$ & 18 \\
\hline R48 & $\cdot \mathrm{OOCH}_{3}+\cdot \mathrm{OOCH}_{3} \rightarrow$ products & $5.0 \times 10^{8}$ & 23 \\
\hline R49 & $\cdot \mathrm{OOCH}_{3}+\mathrm{HO}_{2} \cdot \rightarrow \mathrm{CH}_{3} \mathrm{OH}+{ }^{3} \mathrm{O}+{ }^{3} \mathrm{O}_{2}$ & $5.0 \times 10^{8}$ & 23 \\
\hline R50 & $\cdot \mathrm{OCH}_{3} \rightarrow{ }^{\bullet} \mathrm{CH}_{2} \mathrm{OH}$ & $5.0 \times 10^{5} \mathrm{~s}^{-1}$ & 23 \\
\hline R51 & $\cdot{ }^{\cdot} \mathrm{CH}_{2} \mathrm{OH}+\mathrm{O}_{2} \rightarrow \mathrm{OHCH}_{2} \mathrm{OO} \cdot$ & $4.9 \times 10^{9}$ & 23 \\
\hline R52 & $\mathrm{OHCH}_{2} \mathrm{OO} \cdot \rightarrow \mathrm{HCHO}+\mathrm{HO}_{2}{ }^{\bullet}$ & $10 \mathrm{~s}^{-1}$ & 23 \\
\hline R53 & $\mathrm{OHCH}_{2} \mathrm{OO} \bullet+\mathrm{OH}^{-} \rightarrow \mathrm{HCHO}+\mathrm{O}_{2}^{\bullet-}+\mathrm{H}_{2} \mathrm{O}$ & $1.5 \times 10^{10}$ & 23 \\
\hline R54a & $\mathrm{OHCH}_{2} \mathrm{OO} \bullet+\mathrm{OHCH}_{2} \mathrm{OO} \bullet \rightarrow 2 \mathrm{OHCH}_{2} \mathrm{O}^{\bullet}+\mathrm{O}_{2}$ & $8.9 \times 10^{8}$ & 19 \\
\hline $\mathrm{R} 54 \mathrm{~b}$ & $\mathrm{OHCH}_{2} \mathrm{OO} \cdot+\mathrm{OHCH}_{2} \mathrm{OO} \rightarrow 2 \mathrm{HCOOH}+\mathrm{H}_{2} \mathrm{O}_{2}$ & $1.6 \times 10^{9}$ & 19 \\
\hline R55 & $\mathrm{OHCH}_{2} \mathrm{OO} \cdot+\mathrm{HO}_{2} \cdot \rightarrow \mathrm{CH}_{2}(\mathrm{OH})_{2}+{ }^{3} \mathrm{O}+{ }^{3} \mathrm{O}_{2}$ & $2.0 \times 10^{6}$ & 19 \\
\hline R56 & $\mathrm{CH}_{3} \mathrm{OH}+{ }^{\bullet} \mathrm{OH} \rightarrow{ }^{\bullet} \mathrm{CH}_{2} \mathrm{OH}(93 \%)+{ }^{\circ} \mathrm{OCH}_{3}(7 \%)+\mathrm{H}_{2} \mathrm{O}$ & $9.7 \times 10^{8}$ & 5 \\
\hline R57 & $\begin{array}{l}\text { Major reactions initiated by tert-butyl alcohol } \\
\left(\mathrm{CH}_{3}\right)_{3} \mathrm{COH}+{ }^{\bullet} \mathrm{OH} \rightarrow{ }^{\bullet} \mathrm{CH}_{2} \mathrm{C}\left(\mathrm{CH}_{3}\right)_{2} \mathrm{OH}(95.7 \%)+\left(\mathrm{CH}_{3}\right)_{3} \mathrm{CO} \bullet \\
(4.3 \%)+\mathrm{H}_{2} \mathrm{O}\end{array}$ & $6.0 \times 10^{8}$ & 5 \\
\hline R58 & $\mathrm{CH}_{3} \mathrm{C}(\mathrm{O}) \mathrm{OOH}+\left(\mathrm{CH}_{3}\right)_{3} \mathrm{CO}^{\bullet} \rightarrow \mathrm{CH}_{3} \mathrm{C}(\mathrm{O}) \mathrm{OO} \bullet+\left(\mathrm{CH}_{3}\right)_{3} \mathrm{COH}$ & $1.0 \times 10^{7}$ & 21 \\
\hline R59 & $\cdot{ }^{\circ} \mathrm{CH}_{2} \mathrm{C}\left(\mathrm{CH}_{3}\right)_{3} \mathrm{OH}+\mathrm{O}_{2} \rightarrow \cdot{ }^{\circ} \mathrm{OOCH}_{2} \mathrm{C}\left(\mathrm{CH}_{3}\right)_{2} \mathrm{OH}$ & $5.0 \times 10^{9}$ & 24 \\
\hline R60 & $2^{\bullet} \mathrm{OOCH}_{2} \mathrm{C}\left(\mathrm{CH}_{3}\right)_{2} \mathrm{OH} \rightarrow$ products & $9.0 \times 10^{7}$ & 18 \\
\hline
\end{tabular}




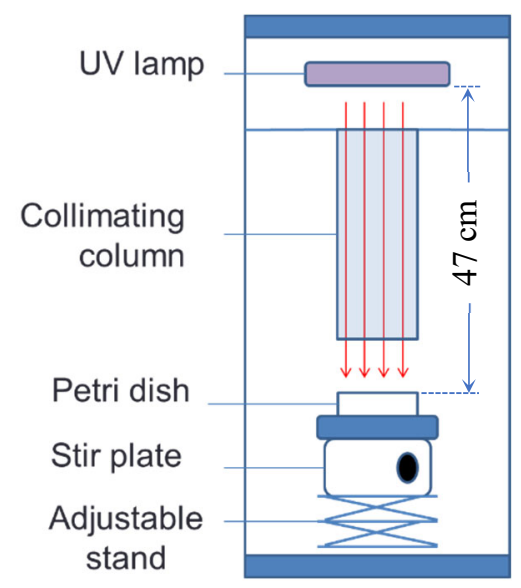

Figure S1. Illustrations of collimated beam photoreactor.
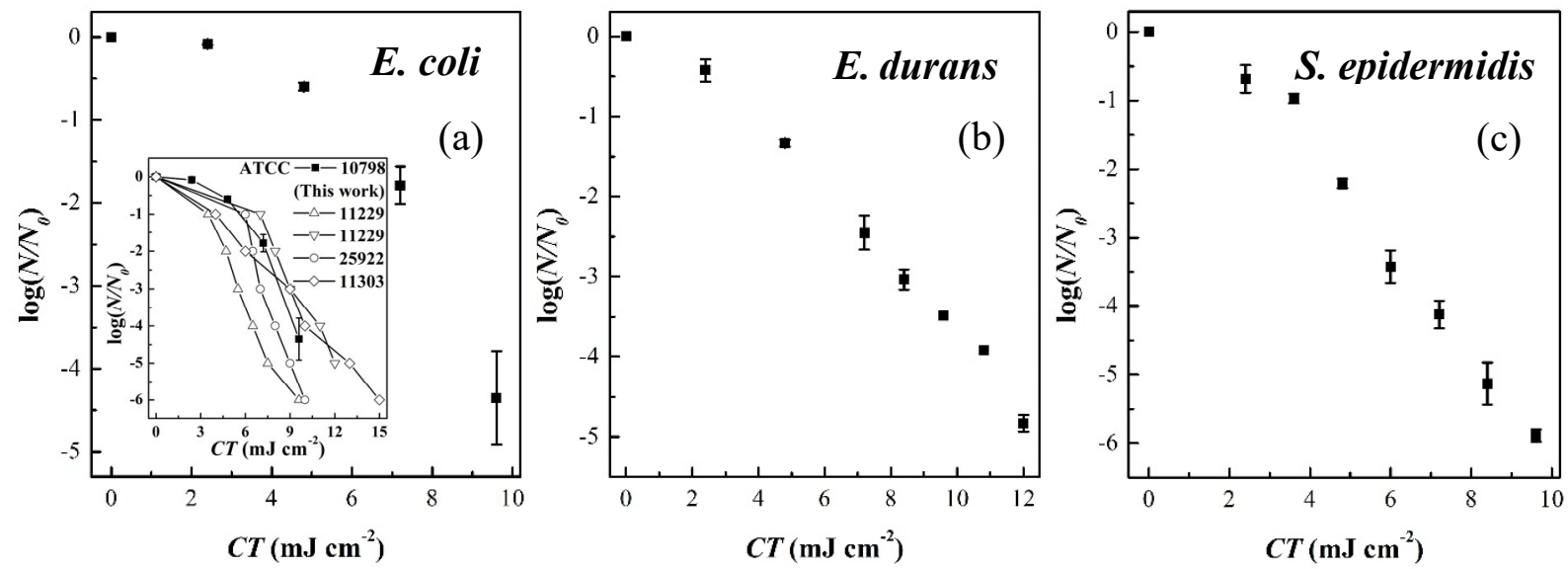

Figure S2. Inactivation of E. coli (a), E. durans (b), and $S$. epidermidis (c) versus $C T$ values of UV irradiance. [Cell $]_{0} \cong 5 \times 10^{7} \mathrm{CFU} \cdot \mathrm{mL}^{-1}$ and $3.0 \mathrm{mM} \mathrm{PB}$ at $\mathrm{pH} 7.1$. In (a), inset shows the comparison of $E$. coli inactivation under $\mathrm{UV}_{254}$ in this work and in references with different strains applied. $^{25}$ 

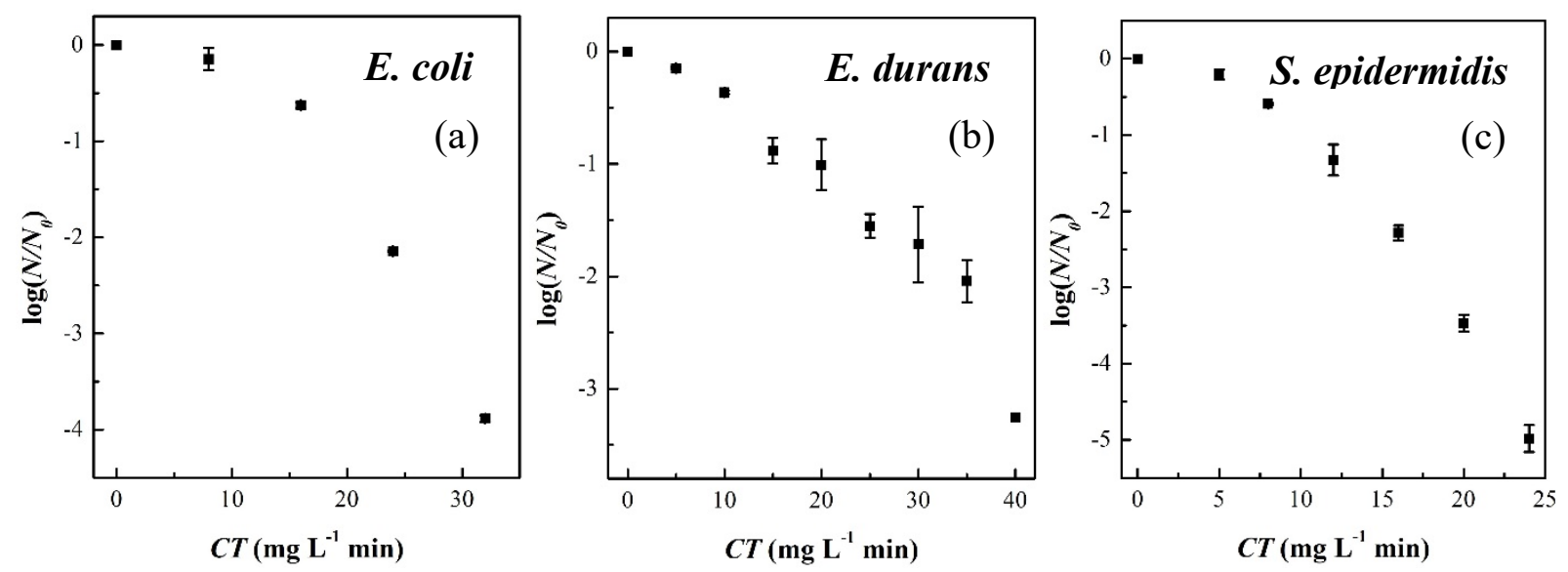

Figure S3. Inactivation of E. coli (a), E. durans (b), and S. epidermidis (c) versus $C T$ values of PAA. $[\text { Cell }]_{0} \cong 5 \times 10^{7} \mathrm{CFU} \cdot \mathrm{mL}^{-1}$ and $3.0 \mathrm{mM} \mathrm{PB}$ at $\mathrm{pH} 7.1$.
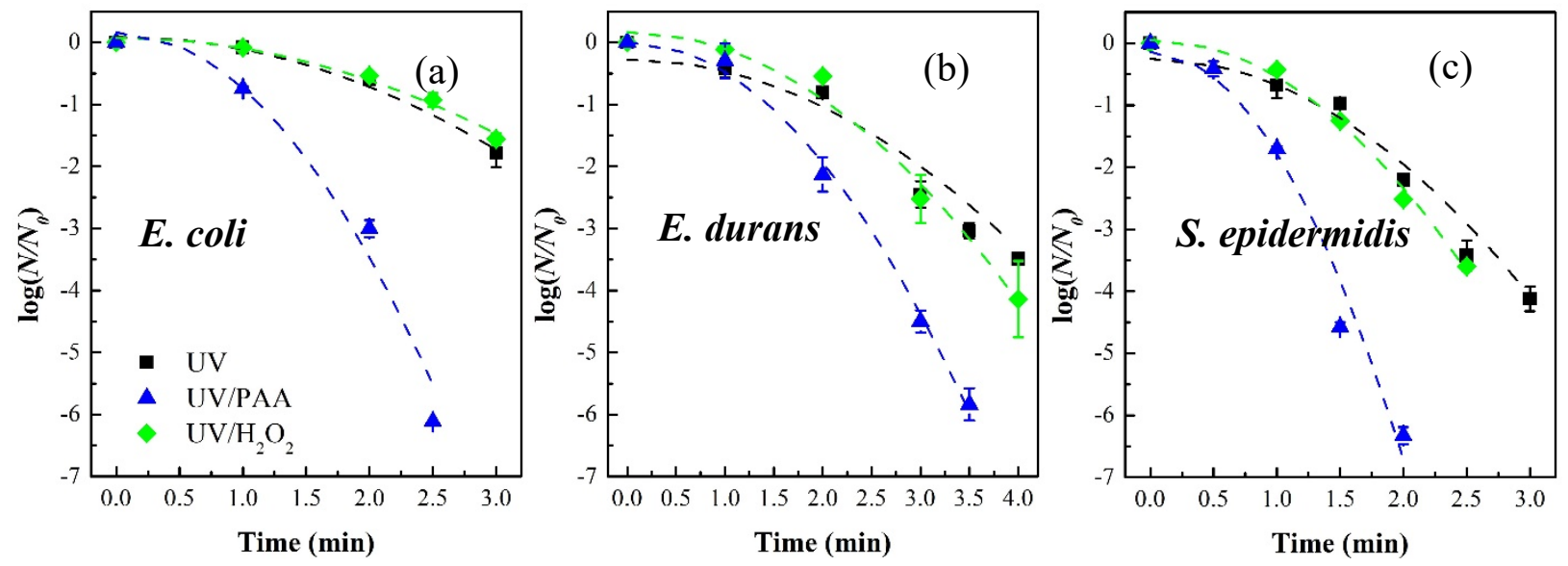

Figure S4. Inactivation of E. coli (a), E. durans (b), and S. epidermidis (c) under UV disinfection (UV), PAA combined with UV (UV/PAA), or $\mathrm{H}_{2} \mathrm{O}_{2}$ combined with $\mathrm{UV}\left(\mathrm{UV} / \mathrm{H}_{2} \mathrm{O}_{2}\right)$. Dashed lines represent the Hom model fitting. In a \& c, [PAA $]_{0}:\left[\mathrm{H}_{2} \mathrm{O}_{2}\right]_{0}=96: 37 \mu \mathrm{M}$ for $(\boldsymbol{\Delta})$ and $\left[\mathrm{H}_{2} \mathrm{O}_{2}\right]_{0}=133$ $\mu \mathrm{M}$ for $(\diamond)$ and; In b, [PAA $]_{0}:\left[\mathrm{H}_{2} \mathrm{O}_{2}\right]_{0}=120: 46 \mu \mathrm{M}$ for $(\Delta)$ and $\left[\mathrm{H}_{2} \mathrm{O}_{2}\right]_{0}=166 \mu \mathrm{M}$ for $(\diamond)$. UV fluence rate $=2.2 \times 10^{-7}$ Einstein $\cdot \mathrm{L}^{-1} \cdot \mathrm{s}^{-1},[\text { Cell }]_{0} \cong 5 \times 10^{7} \mathrm{CFU} \cdot \mathrm{mL}^{-1}$ and $3.0 \mathrm{mM} \mathrm{PB}$ at $\mathrm{pH} 7.1$. 

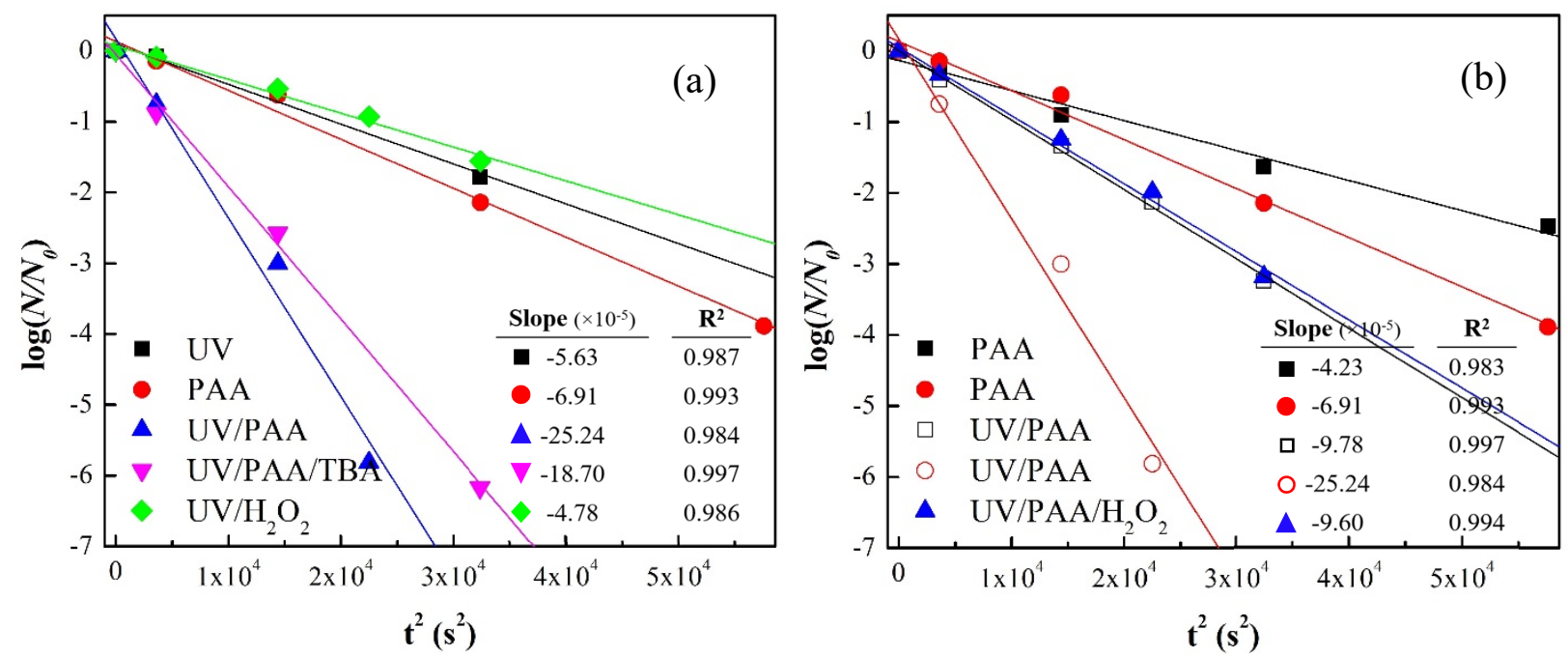

Figure S5. Inactivation of $E$. coli under various disinfection conditions. Solid lines: Hom model fitting under each condition by plotting log survival of E. coli versus $t^{2}$. In a, [PAA $]_{0}:\left[\mathrm{H}_{2} \mathrm{O}_{2}\right]_{0}=$ $96: 37 \mu \mathrm{M}$ for $(\bullet / \mathbf{\Delta} / \mathbf{\nabla}),\left[\mathrm{H}_{2} \mathrm{O}_{2}\right]_{0}=133 \mu \mathrm{M}$ for $(\diamond)$ and $[\mathrm{TBA}]_{0}=10 \mathrm{mM}$; In b, [PAA $]_{0}:\left[\mathrm{H}_{2} \mathrm{O}_{2}\right]_{0}=$ $48: 18.5 \mu \mathrm{M}$ for $(\boldsymbol{\square} / \square)$, [PAA $]_{0}:\left[\mathrm{H}_{2} \mathrm{O}_{2}\right]_{0}=96: 37 \mu \mathrm{M}$ for $(\bullet / 0)$ and $[\mathrm{PAA}]_{0}:\left[\mathrm{H}_{2} \mathrm{O}_{2}\right]_{0}=48: 85 \mu \mathrm{M}$ for (४). UV fluence rate $=2.2 \times 10^{-7}$ Einstein $\cdot \mathrm{L}^{-1} \cdot \mathrm{s}^{-1},[\mathrm{Cell}]_{0} \cong 5 \times 10^{7} \mathrm{CFU} \cdot \mathrm{mL}^{-1}$ and $3.0 \mathrm{mM} \mathrm{PB}$ at $\mathrm{pH}$ 7.1 .
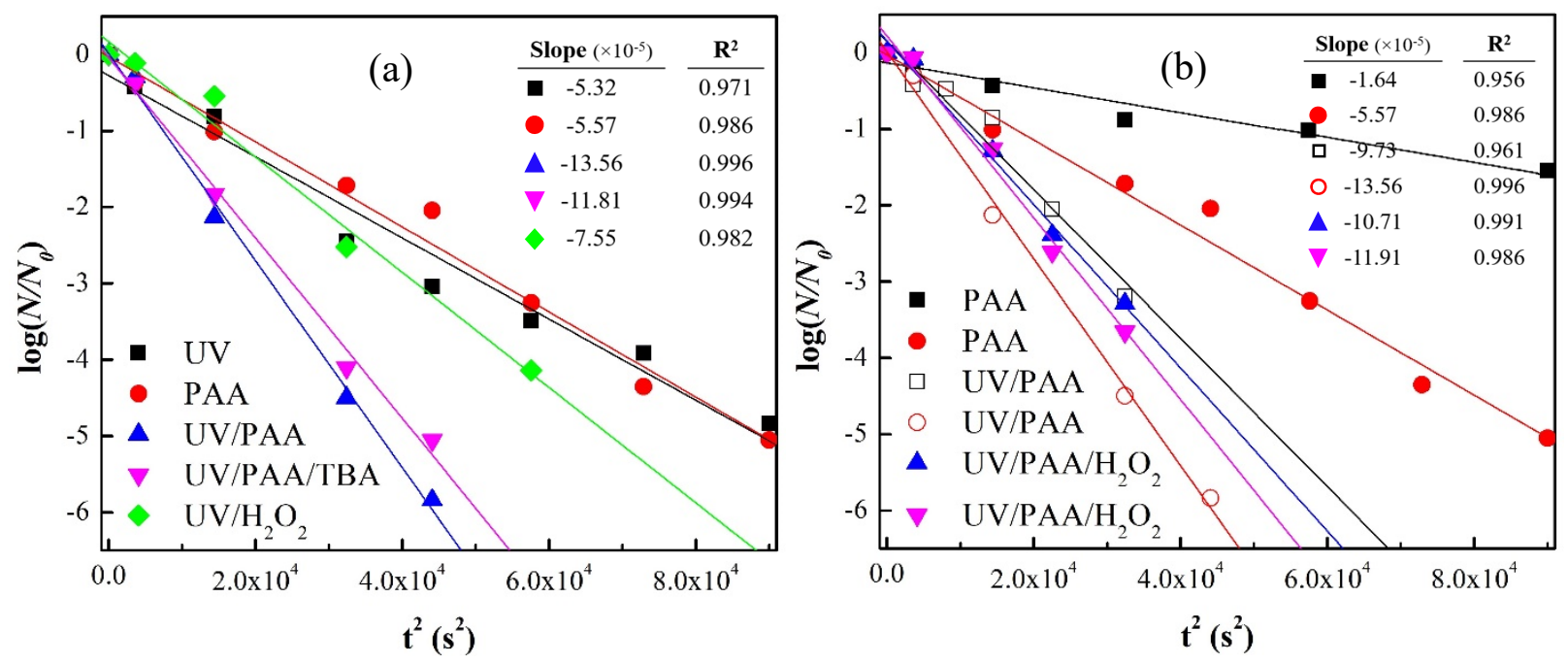

Figure S6. Inactivation of $E$. durans under various disinfection conditions. Solid lines: Hom model fitting under each condition by plotting log survival of $E$. durans versus $t^{2}$. In a, $[\mathrm{PAA}]_{0}:\left[\mathrm{H}_{2} \mathrm{O}_{2}\right]_{0}=$ $120: 46 \mu \mathrm{M}$ for $(\bullet / \mathbf{\Delta} / \nabla),\left[\mathrm{H}_{2} \mathrm{O}_{2}\right]_{0}=166 \mu \mathrm{M}$ for $(\diamond)$ and $[\mathrm{TBA}]_{0}=10 \mathrm{mM}$; In b, [PAA $]_{0}:\left[\mathrm{H}_{2} \mathrm{O}_{2}\right]_{0}=$

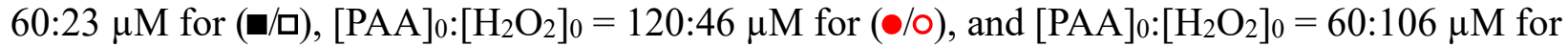
$(\boldsymbol{\Delta})$ and $[\mathrm{PAA}]_{0}:\left[\mathrm{H}_{2} \mathrm{O}_{2}\right]_{0}=60: 157 \mu \mathrm{M}$ for $(\boldsymbol{\nabla})$. UV fluence rate $=2.2 \times 10^{-7}$ Einstein $\cdot \mathrm{L}^{-1} \cdot \mathrm{s}^{-1}$, [Cell $]_{0}$ $\cong 5 \times 10^{7} \mathrm{CFU} \cdot \mathrm{mL}^{-1}$ and $3.0 \mathrm{mM} \mathrm{PB}$ at $\mathrm{pH}$ 7.1. 

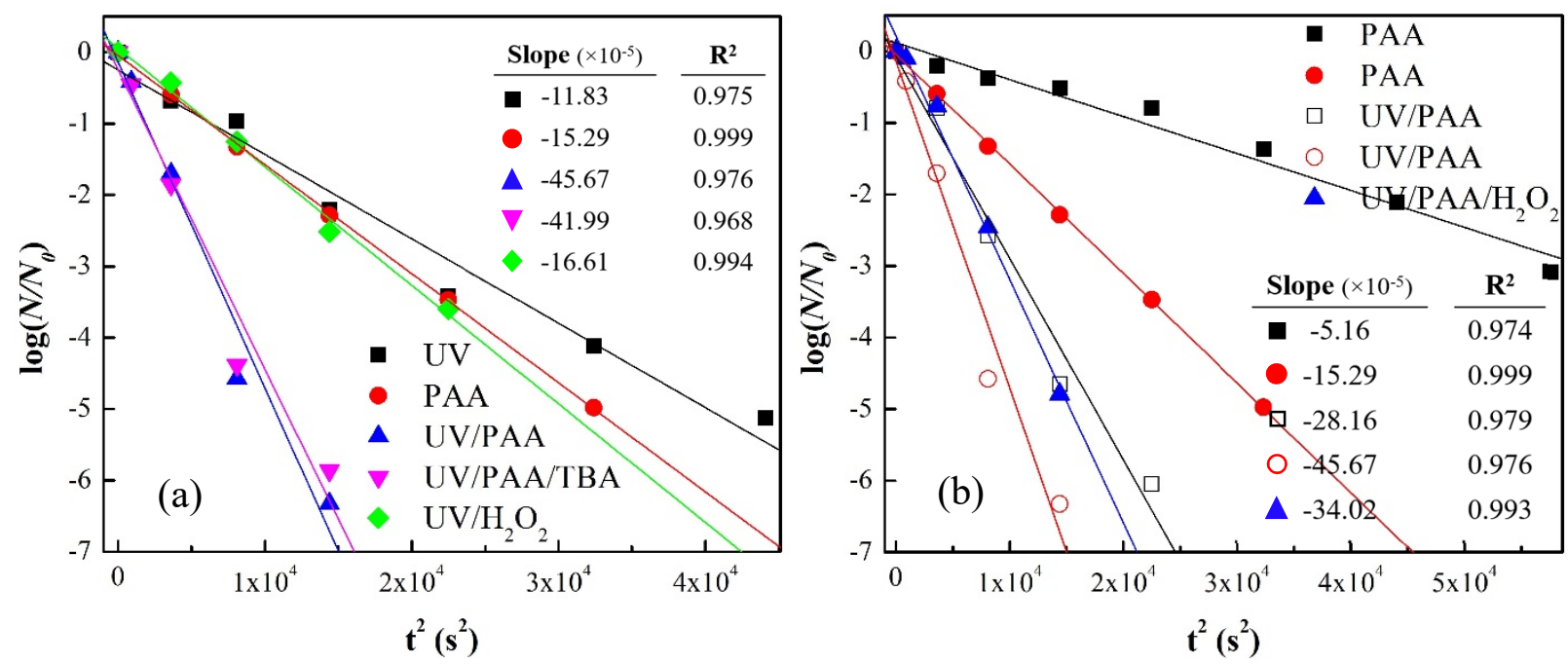

Figure S7. Inactivation of S. epidermidis under various disinfection conditions. Solid lines: Hom model fitting under each condition by plotting $\log$ survival of $S$. epidermidis versus $t^{2}$. In a, $[\mathrm{PAA}]_{0}:\left[\mathrm{H}_{2} \mathrm{O}_{2}\right]_{0}=96: 37 \mu \mathrm{M}$ for $(\boldsymbol{\bullet} / \mathbf{\Delta} / \mathbf{\nabla}),\left[\mathrm{H}_{2} \mathrm{O}_{2}\right]_{0}=133 \mu \mathrm{M}$ for $(\diamond)$ and $[\mathrm{TBA}]_{0}=10 \mathrm{mM}$; In b, $[\mathrm{PAA}]_{0}:\left[\mathrm{H}_{2} \mathrm{O}_{2}\right]_{0}=48: 18.5 \mu \mathrm{M}$ for $(\boldsymbol{\square} / \mathbf{C})$, [PAA $]_{0}:\left[\mathrm{H}_{2} \mathrm{O}_{2}\right]_{0}=96: 37 \mu \mathrm{M}$ for $(\bullet / 0)$ and $[\mathrm{PAA}]_{0}:\left[\mathrm{H}_{2} \mathrm{O}_{2}\right]_{0}$ $=48: 85 \mu \mathrm{M}$ for $(\Lambda)$. UV fluence rate $=2.2 \times 10^{-7}$ Einstein $\cdot \mathrm{L}^{-1} \cdot \mathrm{s}^{-1}$, [Cell $]_{0} \cong 5 \times 10^{7} \mathrm{CFU} \cdot \mathrm{mL}^{-1}$ and $3.0 \mathrm{mM} \mathrm{PB}$ at $\mathrm{pH} 7.1$.

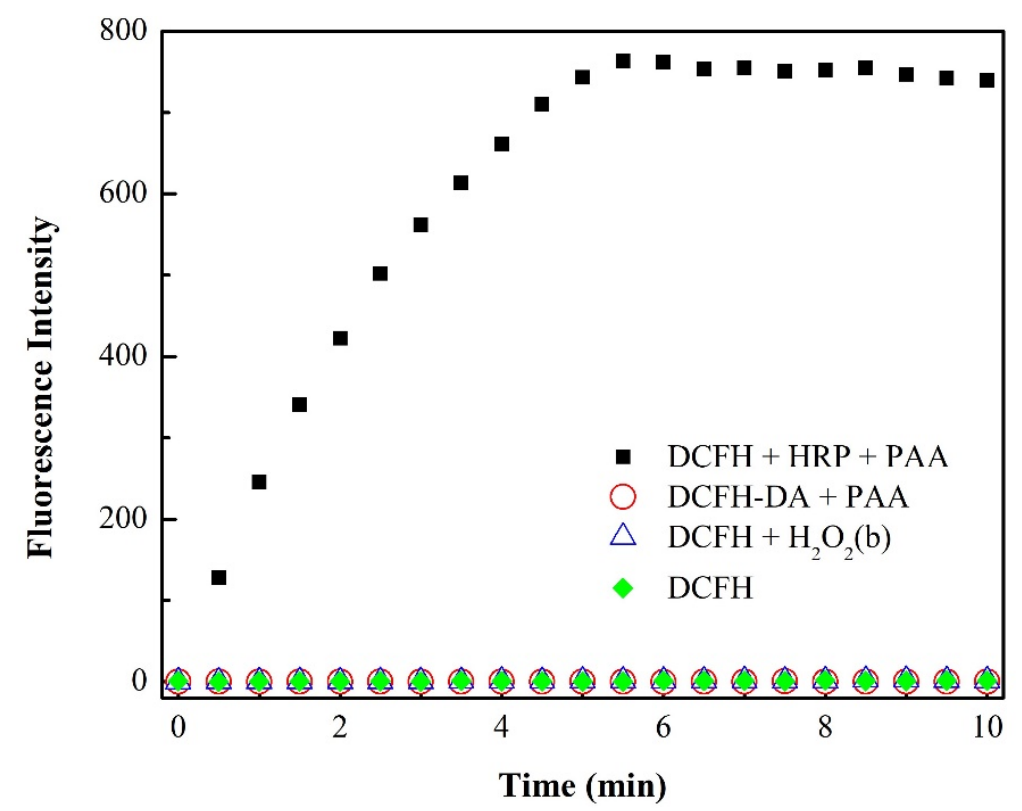

Figure S8. The fluorescence of DCF generated with time after mixing DCFH or DCFH-DA with variable oxidants. $[\mathrm{DCFH}]_{0}=1 \mu \mathrm{M},[\mathrm{HRP}]_{0}=250 \mathrm{unit} / \mathrm{L},[\mathrm{PAA}]_{0}=40 \mu \mathrm{M},\left[\mathrm{H}_{2} \mathrm{O}_{2}(\mathrm{~b})\right]_{0}=15.5$ $\mu \mathrm{M}$ and $\lambda_{\mathrm{Ex} / \mathrm{Em}}=498 / 522 \mathrm{~nm}$. 


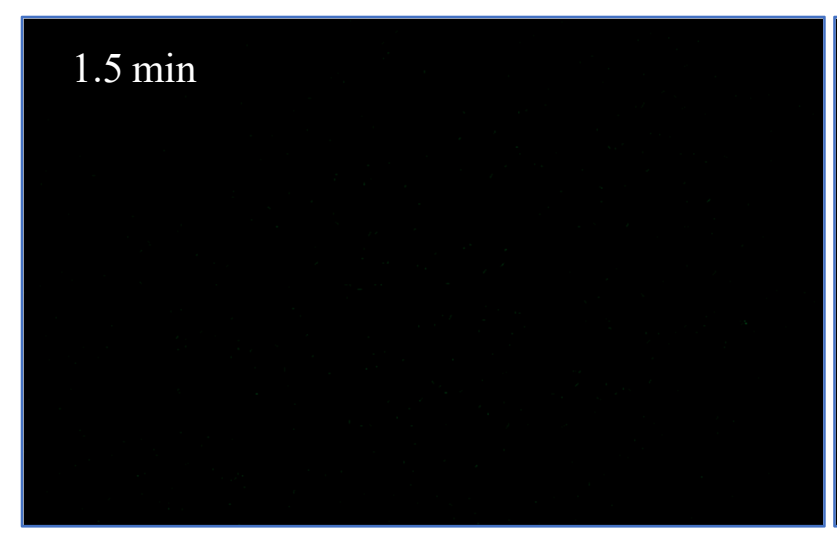

$4 \min$
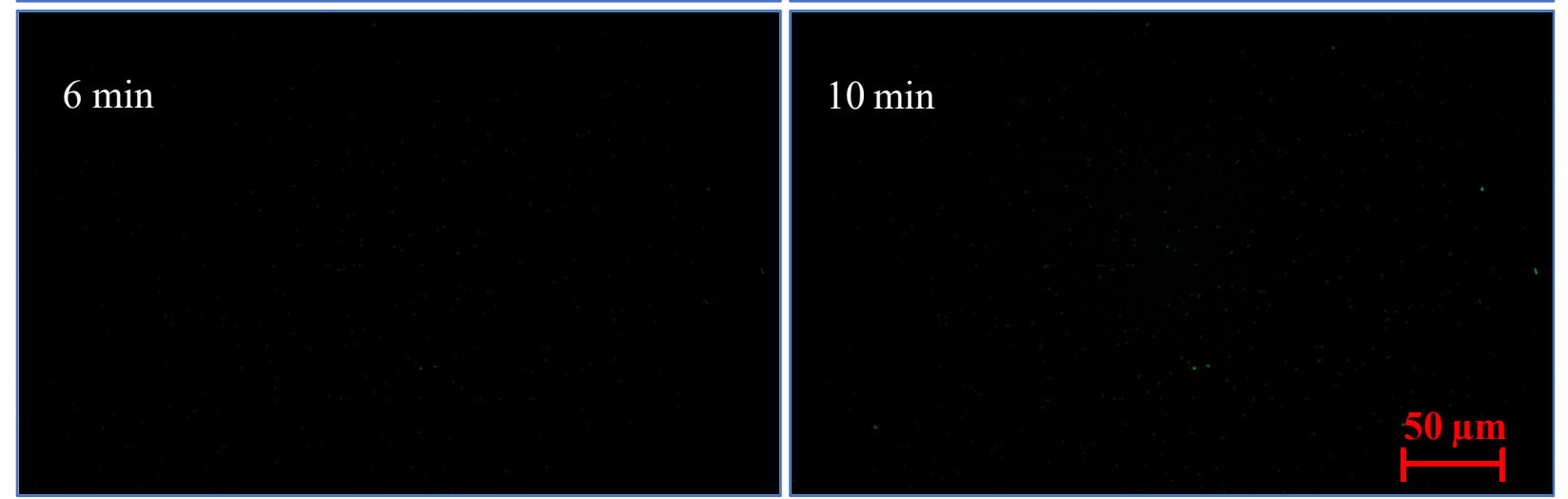

Figure S9. Fluorescence microscope images of DCFH-DA incubated E. coli treated by $\mathrm{H}_{2} \mathrm{O}_{2}$ with time. $\left[\mathrm{H}_{2} \mathrm{O}_{2}\right]_{0}=46 \mu \mathrm{M}$, [DCFH-DA] $=0.3 \mathrm{mM}$ and $30 \mathrm{mM} \mathrm{PB}$. 

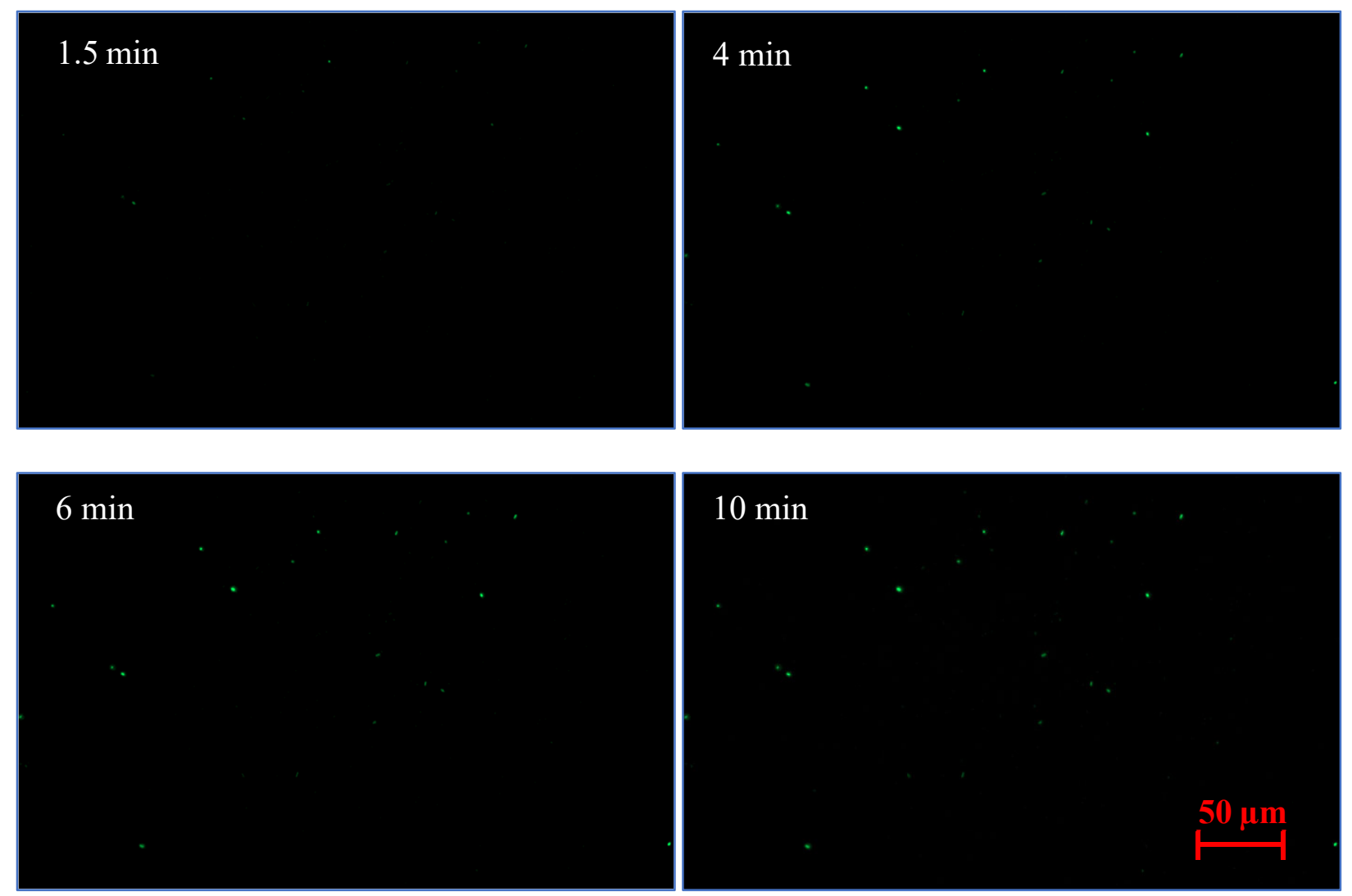

Figure S10. Fluorescence microscope images of DCFH-DA incubated E. coli treated by $\mathrm{H}_{2} \mathrm{O}_{2}$ with time. $\left[\mathrm{H}_{2} \mathrm{O}_{2}\right]_{0}=240 \mu \mathrm{M},[\mathrm{DCFH}-\mathrm{DA}]=0.3 \mathrm{mM}$ and $30 \mathrm{mM}$ PB. 


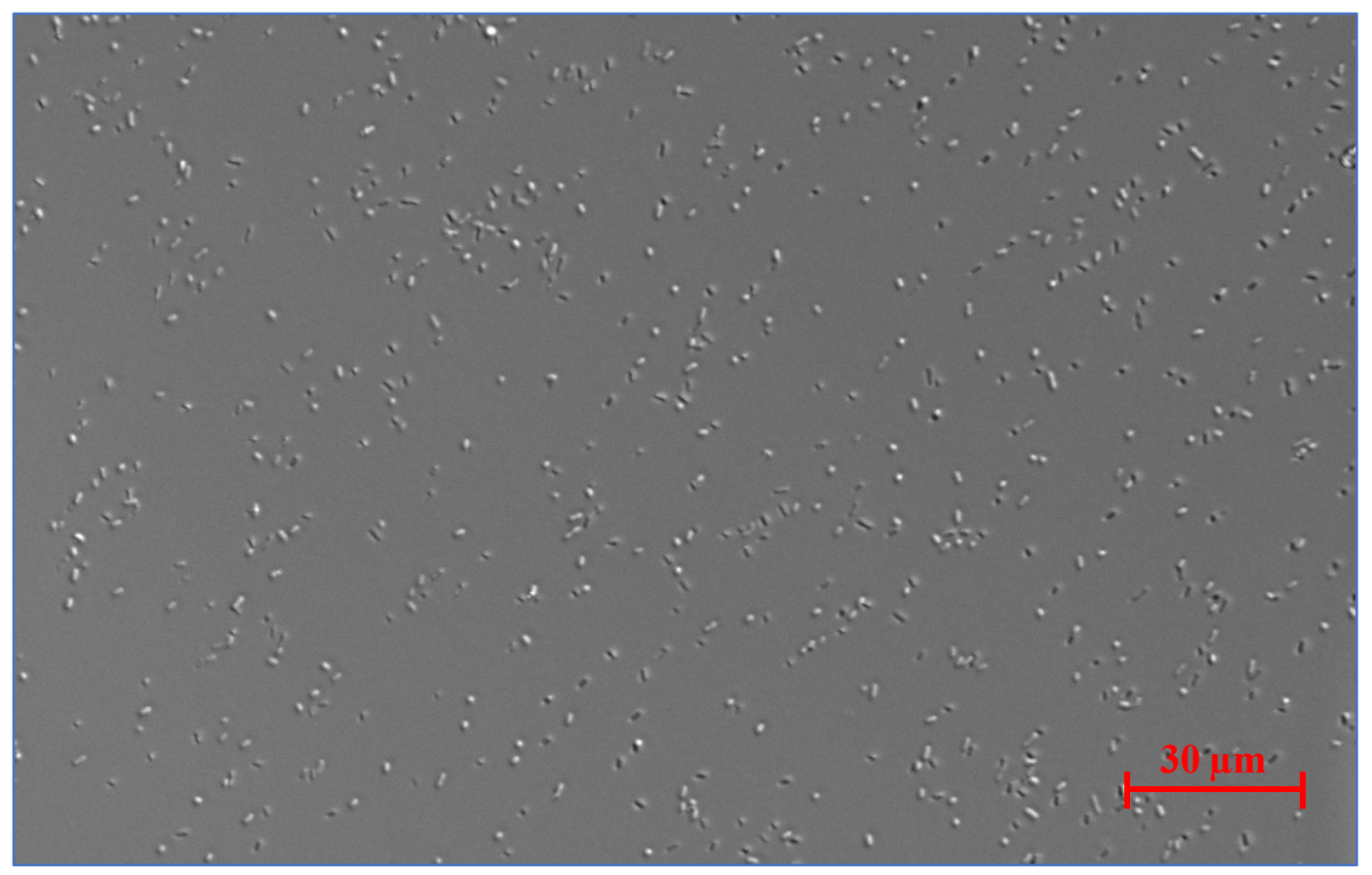

Figure S11. Differential interference contrast (DIC) microscopic image of $E$. coli with [cell] $1 \times 10^{9} \mathrm{CFU} \cdot \mathrm{mL}^{-1}$ in $30 \mathrm{mM} \mathrm{PB}$. 


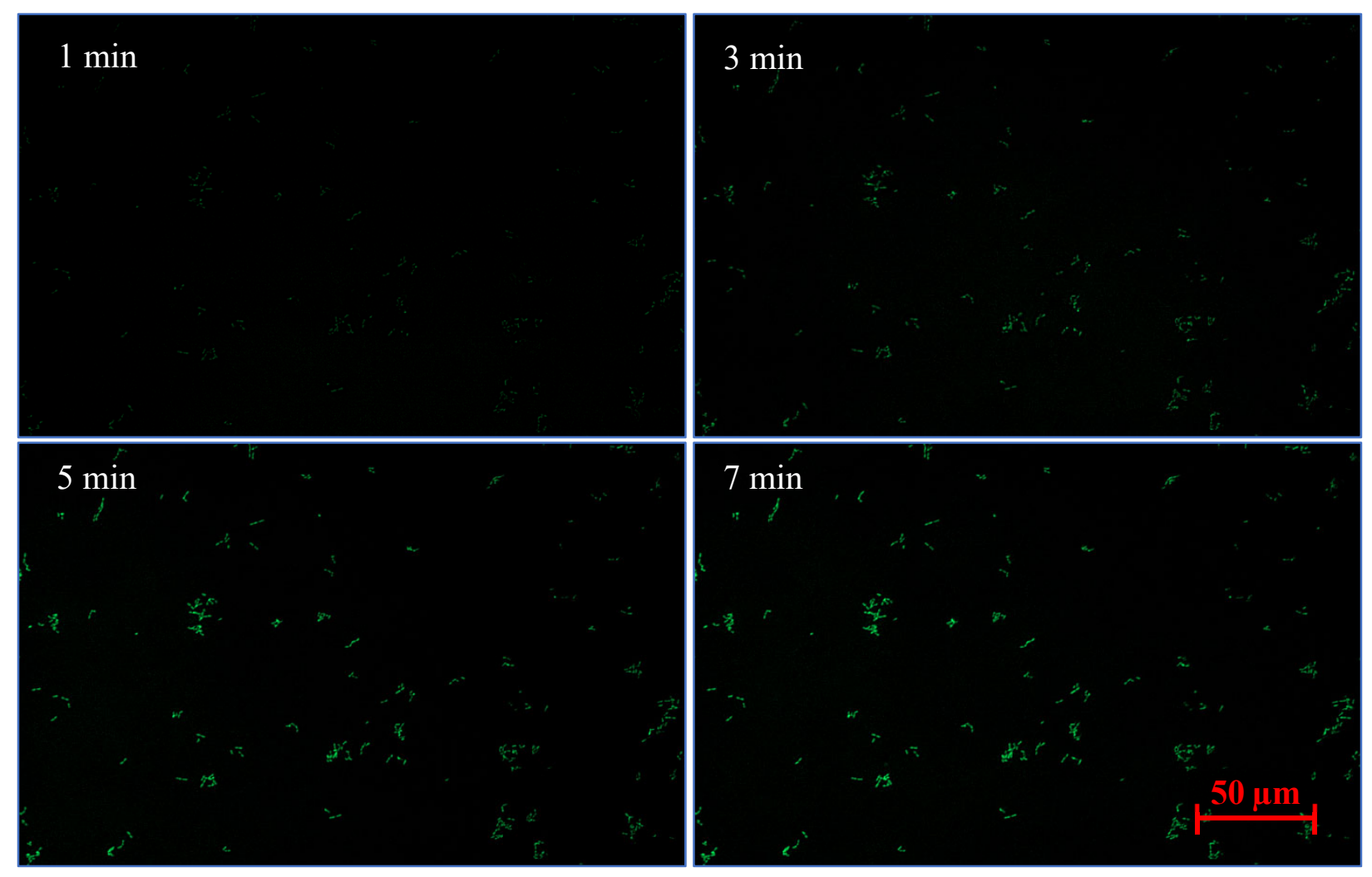

Figure S12. Fluorescence microscope images of DCFH-DA incubated $E$. durans treated by PAA with time. $[\mathrm{PAA}]_{0}=120 \mu \mathrm{M},\left[\mathrm{H}_{2} \mathrm{O}_{2}\right]_{0}=46 \mu \mathrm{M}$, [DCFH-DA $]=0.3 \mathrm{mM}$ and $30 \mathrm{mM} \mathrm{PB}$. 

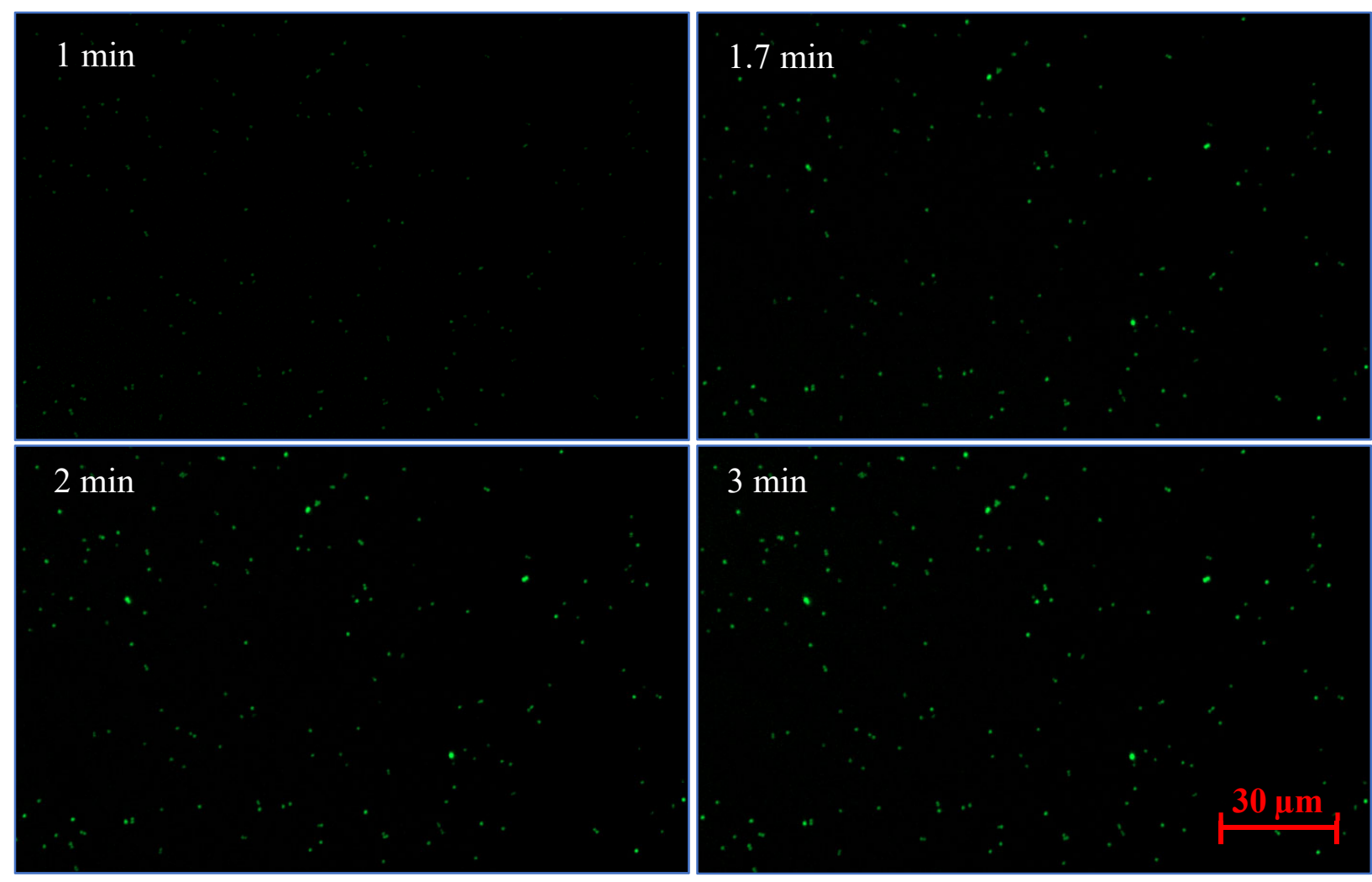

Figure S13. Fluorescence microscope images of DCFH-DA incubated S. epidermidis treated by PAA with time. $[\mathrm{PAA}]_{0}=120 \mu \mathrm{M},\left[\mathrm{H}_{2} \mathrm{O}_{2}\right]_{0}=46 \mu \mathrm{M},[\mathrm{DCFH}-\mathrm{DA}]=0.3 \mathrm{mM}$ and $30 \mathrm{mM} \mathrm{PB}$. 

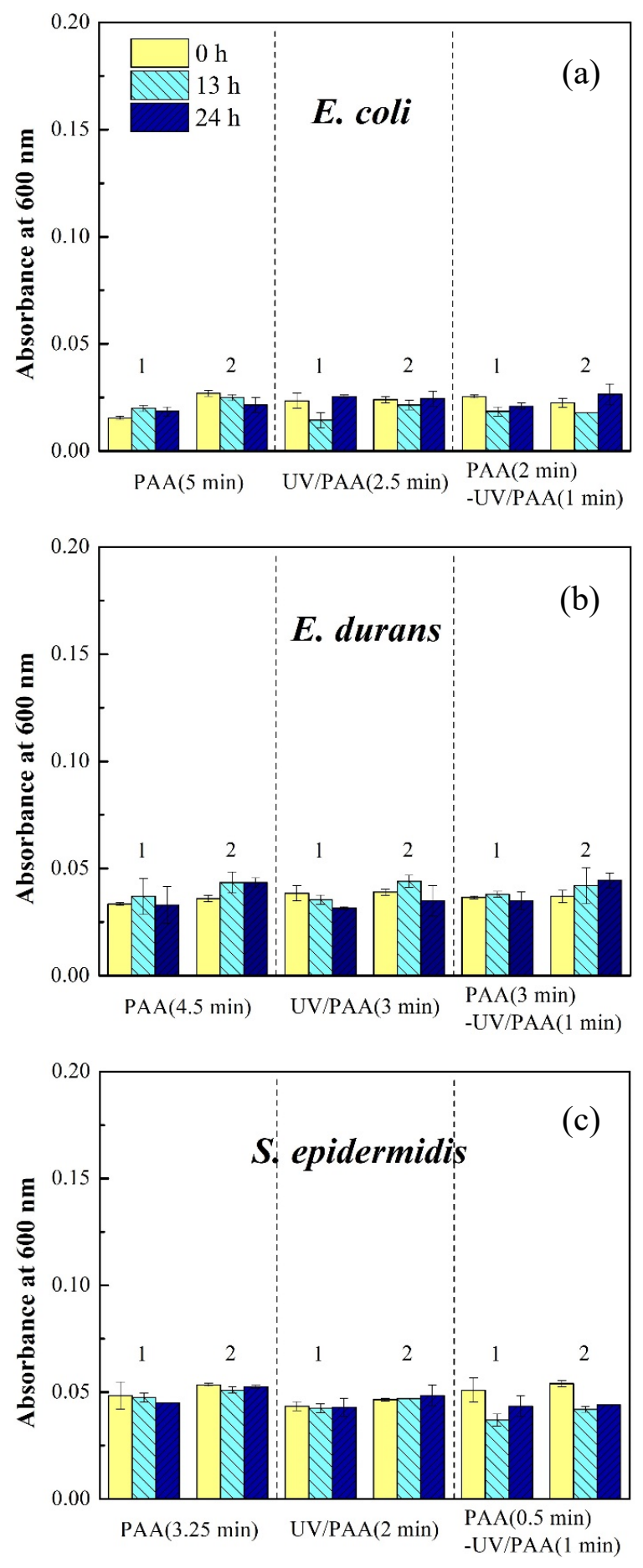

Figure S14. Regrowth test of E. coli (a), E. durans (b), and S. epidermidis (c) by measuring absorbance at $600 \mathrm{~nm}$ at $0 \mathrm{~h}, 13 \mathrm{~h}$, and $24 \mathrm{~h}$ after the bacteria were disinfected under PAA, UV/PAA or PAA-UV/PAA with designed treatment time. The label 1 and 2 on the top of columns represent the residual PAA was and was not quenched by $\mathrm{Na}_{2} \mathrm{~S}_{2} \mathrm{O}_{3}$, respectively, before the test. [PAA] $]_{0}=$ $96 \mu \mathrm{M} \mathrm{(a/c)}$ and $120 \mu \mathrm{M}(\mathrm{b}) ;\left[\mathrm{H}_{2} \mathrm{O}_{2}\right]_{0}=37 \mu \mathrm{M}(\mathrm{a} / \mathrm{c})$ and $46 \mu \mathrm{M}(\mathrm{b})$. UV fluence rate $=2.2 \times 10^{-7}$ Einstein $\cdot \mathrm{L}^{-1} \cdot \mathrm{s}^{-1},[\mathrm{Cell}]_{0} \cong 5 \times 10^{7} \mathrm{CFU} \cdot \mathrm{mL}^{-1}$ and $3.0 \mathrm{mM} \mathrm{PB}$ at $\mathrm{pH} 7.1$. 


\section{REFERENCES}

1. Sun, P.; Zhang, T.; Mejia-Tickner, B.; Zhang, R.; Cai, M.; Huang, C.-H., Rapid disinfection by peracetic acid combined with UV irradiation. Environ. Sci. Technol. Let. 2018, 5 (6), 400-404.

2. Cai, M.; Sun, P.; Zhang, L.; Huang, C.-H., UV/peracetic acid for degradation of pharmaceuticals and reactive species evaluation. Environ. Sci. Technol. 2017, 51 (24), 1421714224.

3. Zhang, T.; Huang, C.-H., Modeling the kinetics of UV/peracetic acid advanced oxidation process. Environ. Sci. Technol., 2020, 54 (12), 7579-7590.

4. Zhang, T.; Cheng, L.; Ma, L.; Meng, F.; Arnold, R. G.; Saez, A. E., Modeling the oxidation of phenolic compounds by hydrogen peroxide photolysis. Chemosphere 2016, 161, 349-357.

5. Buxton, G. V.; Greenstock, C. L.; Helman, W. P.; Ross, A. B., Critical review of rate constants for reactions of hydrated electrons, hydrogen atoms and hydroxyl radicals $\left(\cdot \mathrm{OH} / \mathrm{O}^{-}\right)$in aqueous solution. J. Phys. Chem. Ref. Data 1988, 17, 513-886.

6. Holeman, J.; Bjergbakke, E.; Sehested, K., The importance of radical-radical reactions in pulse radiolysis of aqueous carbonate/bicarbonate. Proc. Tihany Symp. Radiat. Chem. 1987, 1, 149-153.

7. Bielski, B. H. J.; Cabelli, D. E.; Arudi, R. L.; Ross, A. B., Reactivity of $\mathrm{HO}_{2} / \mathrm{O}_{2}$ radicals in aqueous solution. J. Phys. Chem. Ref. Data 1985, 14 (4), 1041-1100.

8. Weinstein, J.; Bielski, B. H. J., Kinetics of the interaction of perhydroxyl and superoxide radicals with hydrogen peroxide. The Haber-Weiss reaction. J. Am. Chem. Soc. 1979, 101, 58-62. 9. Eriksen, T. E.; Lind, J.; Merenyi, G., On the acid-base equilibrium of the carbonate radical. Radiat. Phys. Chem. 1985, 26, 197-199.

10. Neta, P.; Huie, R. E.; Ross, A. B., Rate constants for reactions of inorganic radicals in aqueous solution. J. Phys. Chem. Ref. Data 1988, 17 (3), 1027-1284.

11. Perry, R.; Green, D.; Maloney, J., Perry's Chemical Engineerings' Handbook. 5th ed.; McGraw-Hill: New York, 1981.

12. Housecroft, C. E.; Sharpe, A. G., Inorganic Chemistry. 2nd ed.; Prentice-Pearson-Hall: 2005.

13. Greenwood, N. N.; Earnshaw, A., Chemistry of the Elements. 2nd ed.; ButterworthHeinemann: 1997.

14. Maruthamuthu, P.; Neta, P., Phosphate radicals. Spectra, acid-base equilibria and reactions with inorganic compounds. J. Phys. Chem. 1978, 82 (6), 710-713.

15. Nakashima, M.; Hayon, E., Rates of reaction of inorganic phosphate radicals in solution. J. Phys. Chem. 1970, 74 (17), 3290-3291.

16. Yang, Y.; Pignatello, J. J.; Ma, J.; Mitch, W. A., Comparison of halide impacts on the efficiency of contaminant degradation by sulfate and hydroxyl radical-based advanced oxidation processes (AOPs). Environ. Sci. Technol. 2014, 48 (4), 2344-2351.

17. Schuchmann, M. N.; Zegota, H.; von Sonntag, C., Acetate peroxyl radicals, ${ }^{\circ} \mathrm{O}_{2} \mathrm{CH}_{2} \mathrm{COO}_{2}{ }^{-}$: A study on the $\gamma$-radiolysis and pulse radiolysis of acetate in oxygenated aqueous solutions. $Z$. Naturforsch., B: J. Chem. Sci. 1985, 40b, 215-221.

18. Neta, P.; Huie, R. E.; Ross, A. B., Rate constants for reactions of peroxyl radicals in fluid solutions. J. Phys. Chern. Ref. Data 1990, 19 (2), 413-513. 
19. Kamath, D.; Mezyk, S. P.; Minakata, D., Elucidating the elementary reaction pathways and kinetics of hydroxyl radical-induced acetone degradation in aqueous phase advanced oxidation processes. Environ. Sci. Technol. 2018, 52 (14), 7763-7774.

20. Ervens, B.; Gligorovski, S.; Herrmann, H., Temperature-dependent rate constants for hydroxyl radical reactions with organic compounds in aqueous solutions. Phys. Chem. Chem. Phys. 2003, $5,1811-1824$.

21. Chateauneuf, J.; Lusztyk, J.; Ingold, K. U., Spectroscopic and kinetic characteristics of aroyloxyl radicals. 1. The 4-methoxybenzoyloxyl radical. J. Am. Chem. Soc. 1988, 110, 2877-2885. 22. Lu, Z.; Continetti, R. E., Dynamics of the acetyloxyl radical studied by dissociative photodetachment of the acetate anion. J. Phys. Chem. A 2004, 108 (45), 9962-9969.

23. Schuchmann, H.-P.; von Sonntag, C., Methylperoxyl radicalsL A study of the $\gamma$-radiolysis of methane in oxygenated aqueous solutions. Z. Naturforsch., B: J. Chem. Sci. 1984, 39 (2), $217-$ 221.

24. Chakir, A.; Ganne, J. P.; Roth, E.; Brion, J.; Daumont, D., Study of $\left(\mathrm{CH}_{3}\right)_{2} \mathrm{C}(\mathrm{OH}) \mathrm{CH}_{2} \mathrm{O}_{2}$ using modulated photolysis: ultra-violet spectrum and self-reaction kinetics. Phys. Chem. Chem. Phys. 2004, 6, 3389-3395.

25. Chevrefils, G.; Caron, E.; Wright, H.; Sakamoto, G.; Payment, P.; Barbeau, B.; Cairns, B., $\mathrm{UV}$ dose required to achieve incremental $\log$ inactivation of bacteria, protozoa and viruses. IUVA News 2006, 8 (1), 38-45. 